\title{
Activity Exerted by a Testosterone Derivative on Myocardial Injury Using an Ischemia/Reperfusion Model
}

\author{
Figueroa-Valverde Lauro, ${ }^{1}$ Díaz-Cedillo Francisco, ${ }^{2}$ García-Cervera Elodia, ${ }^{1}$ \\ Pool-Gómez Eduardo, ${ }^{1}$ López-Ramos Maria, ${ }^{1}$ Rosas-Nexticapa Marcela, ${ }^{3}$ \\ Hau-Heredia Lenin, ${ }^{1}$ Sarabia-Alcocer Betty, ${ }^{4}$ and Velázquez-Sarabia Betty Monica ${ }^{4}$ \\ ${ }^{1}$ Laboratory of Pharmaco-Chemistry, Faculty of Chemical Biological Sciences, University Autonomous of Campeche, \\ Avenida Agustín Melgar s/n, Colonia Buenavista, 24039 San Francisco de Campeche, CAM, Mexico \\ ${ }^{2}$ Escuela Nacional de Ciencias Biológicas del Instituto Politéecnico Nacional, Prolongación de Carpio y Plan de Ayala s/n, \\ Col. Santo Tomas, 11340 Mexico City, DF, Mexico \\ ${ }^{3}$ Facultad de Nutrición, Médicos y Odontologos s/n, Unidad del Bosque, 91010 Xalapa, VER, Mexico \\ ${ }^{4}$ Faculty of Medicine, University Autonomous of Campeche, Avenida Patricio Trueba de Regil s/ $n$, Col Lindavista, \\ 24090 San Francisco de Campeche, CAM, Mexico
}

Correspondence should be addressed to Figueroa-Valverde Lauro; lauro_1999@yahoo.com

Received 19 January 2014; Revised 4 March 2014; Accepted 5 March 2014; Published 16 April 2014

Academic Editor: Joen-Rong Sheu

Copyright (C) 2014 Figueroa-Valverde Lauro et al. This is an open access article distributed under the Creative Commons Attribution License, which permits unrestricted use, distribution, and reproduction in any medium, provided the original work is properly cited.

Some reports indicate that several steroid derivatives have activity at cardiovascular level; nevertheless, there is scarce information about the activity exerted by the testosterone derivatives on cardiac injury caused by ischemia/reperfusion (I/R). Analyzing these data, in this study, a new testosterone derivative was synthetized with the objective of evaluating its effect on myocardial injury using an ischemia/reperfusion model. In addition, perfusion pressure and coronary resistance were evaluated in isolated rat hearts using the Langendorff technique. Additionally, molecular mechanism involved in the activity exerted by the testosterone derivative on perfusion pressure and coronary resistance was evaluated by measuring left ventricular pressure in the absence or presence

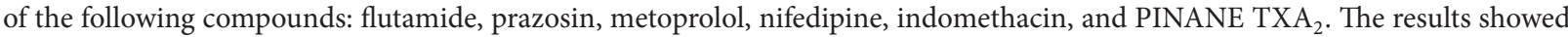
that the testosterone derivative significantly increases $(P=0.05)$ the perfusion pressure and coronary resistance in isolated heart. Other data indicate that the testosterone derivative increases left ventricular pressure in a dose-dependent manner $(0.001-100 \mathrm{nM})$; however, this phenomenon was significantly inhibited $(P=0.06)$ by indomethacin and PINANE-TXA $2(P=0.05)$ at a dose of $1 \mathrm{nM}$. In conclusion, these data suggest that testosterone derivative induces changes in the left ventricular pressure levels through thromboxane receptor activation.

\section{Introduction}

Several reports indicate that myocardial infarction is a major cause of death and disability worldwide $[1,2]$; this cardiovascular disease is due to cell death of cardiac myocytes caused by prolonged myocardial ischemia. Acute myocardial infarction can produce alterations in the topography of both the infarcted and noninfarcted regions of the ventricle [3]. There are some reports which show that the most effective method of limiting necrosis is restoration of blood flow; however, the effects of reperfusion itself may also be associated with tissue injury [4]. A study [5] showed that ischemic preconditioning (PC) upregulates the expression and activity of COX-2 in the heart and that this increase in COX2 activity mediates the protective effects of the late phase of PC against both myocardial stunning and myocardial infarction. Another study [6] indicates that activation of COX-2 produces cardioprotection via synthesis or release of prostanoids such as $\mathrm{PGI}_{2}$ and $\mathrm{PGE}_{2}$ which induce a cardiac protective effect against ischemia-reperfusion injury in experimental animals [7-9]. It is important to mention that there are studies which suggest that the release of these prostanoids may be the result of the effect induced by some steroids on the COX-2 activity; this phenomenon results in 
a decrease in the ischemia-reperfusion injury [10-13]. For example, there is a study which shows that $17 \beta$-estradiol reduced injury by ischemia/reperfusion via activation of $\mathrm{PGI}_{2}$ in an animal model [14]. However, another data showed that administration of other types of steroid (testosterone) is associated with a reduced susceptibility to myocardial ischemia and this phenomenon results in the regulation of intracellular calcium levels on ischemia/reperfusion injury [15]. In addition, another study shows that testosterone exerted activation of STAT3 (signal transducers and activators of transcription 3) and SOCS3 (suppressor of cytokine signaling 3) after ischemia/reperfusion injury [16]. Another report indicates that testosterone indirectly regulates the activation of Akt (protein kinase) during cardiac ischemia/reperfusion [17]. However, other reports suggest that endogenous testosterone may have a negative effect on the heart subjected to acute ischemia/reperfusion via androgen receptor $[18,19]$. Furthermore, a study [20] demonstrated that administration of a derivative of testosterone (nandrolone) increases ischemia/reperfusion by changes in the concentrations of both AMP (adenosine monophosphate) and TNF $\alpha$ (tumor necrosis factor alpha). Another data indicate that another type of testosterone derivative (dehydroepiandrosterone) regulates gene expression of both VEGF (vascular endothelial growth factor) and interleukins (IL-1 and IL-6) on ischaemia/reperfusion injury [21]. All these experimental results indicate that testosterone and its derivatives exert effects on ischemia/reperfusion injury; however, the cellular site and actual molecular mechanisms of testosterone and its derivatives are very confusing; therefore, data are needed for characterizing the activity induced by this steroid and its derivative on ischemia-reperfusion injury. To provide this information, the present study was designed to investigate the effects of testosterone and its derivative in an ischemia/reperfusion injury model. In addition, the activity of testosterone and its derivative on perfusion pressure and coronary resistance were evaluated in isolated rat hearts using the Langendorff technique. In order to evaluate the molecular mechanism involved in the activity induced by the testosterone derivative on left ventricular pressure the following compounds were used as pharmacological tools: flutamide (androgenic receptor antagonist) [22], prazosin ( $\alpha_{1}$ adrenoreceptor antagonist) [23], metoprolol (selective $\beta_{1}$ receptor blocker) [24], nifedipine (antagonist of calciumchannel) [25], indomethacin (a nonselective inhibitor of cyclooxygenase) [26], and PINANE TXA 2 (thromboxane receptor antagonist) [27].

\section{Material and Methods}

2.1. Chemical Synthesis. The compounds evaluated in this study were purchased from Sigma-Aldrich Co., Ltd. The melting point for the testosterone derivative was determined with an Electrothermal (900 model). Infrared spectra (IR) were recorded using $\mathrm{KBr}$ pellets on a Perkin Elmer Lambda 40 spectrometer. ${ }^{1} \mathrm{H}$ and ${ }^{13} \mathrm{C}$ NMR (nuclear magnetic resonance) spectra were recorded on a Varian VXR-300/5 FT NMR spectrometer at 300 and $75.4 \mathrm{MHz}$ (megahertz) in $\mathrm{CDCl}_{3}$ (deuterated chloform) using TMS (tetramethylsilane) as internal standard. EIMS (electron impact mass spectroscopy) spectra were obtained with a Finnigan Trace Gas Chromatography Polaris Q Spectrometer. Elementary analysis data were acquired from a Perkin Elmer Ser. II CHNS/0 2400 elemental analyzer.

2.1.1. Synthesis of 1-[4-(2-Amino-ethylimino)-4-(4-fluorocyclohexyl)-butyl]-4-(4-chloro-phenyl)-piperidin-4-ol (Compound 3). A solution of haloperidol (100 mg, $0.26 \mathrm{mmol})$, ethylenediamine $(80 \mu \mathrm{L}, 1.19 \mathrm{mmol})$, and boric acid $(40 \mathrm{mg}$, $0.65 \mathrm{mmol}$ ) in $10 \mathrm{~mL}$ of methanol was stirred for $72 \mathrm{~h}$ at room temperature. The reaction mixture was evaporated to dryness under reduced pressure; the residue washed 4 times with water. Then the precipitate was separated and dried at room temperature.

2.1.2. Synthesis of 4-(4-Chloro-phenyl)-1-\{4-(4-fluoro-phenyl)4-[2-(17-hydroxy-10,13-dimethyl-1,2,6,7,8,9,10,11,12,13,14,15,16, 17-tetradecahydro-cyclopenta[a]phenanthren-3-ylideneamino)-ethylimino]-butyl-piperidin-4-ol (Compound 5). A solution of compound 3 (100 mg, $0.24 \mathrm{mmol})$, testosterone (70 $\mathrm{mg}, 0.24 \mathrm{mmol}$ ), and boric acid $(40 \mathrm{mg}, 0.65 \mathrm{mmol})$ in $10 \mathrm{~mL}$ of methanol was stirred for $72 \mathrm{~h}$ at room temperature. The reaction mixture was evaporated to dryness under reduced pressure; the residue washed 3 times with water. Then the precipitate was separated and dried at room temperature.

2.2. Biological Method. All experimental procedures and protocols used in this investigation were reviewed and approved by the Animal care and use Committee of University Autonomous of Campeche (no. PI-420/12) and were in accordance with the Guide for the Care and Use of Laboratory Animals [28]. Male Wistar rats $(n=105)$, weighing 200-250 g, were obtained from University Autonomous of Campeche.

2.3. Reagents. All drugs were dissolved in methanol and different dilutions were obtained using Krebs-Henseleit solution $(\leq 0.01 \%, \mathrm{v} / \mathrm{v})$.

2.4. Experimental Design. Briefly, the male rat (200-250 g) was anesthetized by injecting them with pentobarbital at a dose rate of $50 \mathrm{mg} / \mathrm{Kg}$ body weight. Then the chest was opened, and a loose ligature passed through the ascending aorta. The heart was then rapidly removed and immersed in ice cold physiologic saline solution. The heart was trimmed of noncardiac tissue and retrograde perfused via a noncirculating perfusion system at a constant flow rate. The perfusion medium was the Krebs-Henseleit solution $(\mathrm{pH}=$ $7.4,37^{\circ} \mathrm{C}$ ) composed of (mmol) $117.8, \mathrm{NaCl} ; 6, \mathrm{KCl} ; 1.75$, $\mathrm{CaCl}_{2} ; 1.2, \mathrm{NaHPO}_{4} ; 1.2, \mathrm{MgSO}_{4} ; 24.2, \mathrm{NaHCO}_{3} ; 5$, glucose; 7 and 5 , sodium pyruvate. The solution was actively bubbled with a mixture of $\mathrm{O}_{2} / \mathrm{CO}_{2}(95: 5 / 5 \%)$. The coronary flow was adjusted with a variable speed peristaltic pump. An initial perfusion rate of $15 \mathrm{~mL} / \mathrm{min}$ for $5 \mathrm{~min}$ was followed by a $15 \mathrm{~min}$ equilibration period at a perfusion rate of 
$10 \mathrm{~mL} / \mathrm{min}$. All experimental measurements were done after this equilibration period.

2.5. Perfusion Pressure. Evaluation of measurements of perfusion pressure changes induced by drugs administration in this study was assessed using a pressure transducer connected to the chamber where the hearts were mounted and the results entered into a computerized data capture system (Biopac).

2.6. Inotropic Activity. Contractile function was assessed by measuring left ventricular developed pressure (LV/dP), using a saline-filled latex balloon $(0.01 \mathrm{~mm}$, diameter $)$ inserted into the left ventricle via the left atrium. The latex balloon was bound to cannula which was linked to pressure transducer that was connected with the MP100 data acquisition system.

\subsubsection{First Stage}

Activity Induced by Testosterone and Its Derivative Using an Ischemia/Reperfusion Model. After 15 minutes of equilibration time, the hearts were subjected to ischemia for 30 minutes by turning off the perfusion system [29]. After this period, the system was restarted and the hearts were reperfused by 30 minutes with Krebs-Henseleit solution. The hearts were randomly divided into 3 major treatment groups with $n=9$.

Group I. Hearts were subjected to ischemia/reperfusion but received vehicle only (Krebs-Henseleit solution).

Group II. Hearts were subjected to ischemia/reperfusion and treated with testosterone at a dose of $0.001 \mathrm{nM}$ before ischemia period (for 10 minutes) and during the entire period of reperfusion.

Group III. Hearts were subjected to ischemia/reperfusion and treated with the testosterone derivative at a dose of $0.001 \mathrm{nM}$ before ischemia period (for 10 minutes) and during the entire period of reperfusion.

It is noteworthy that, at the end of each experiment, the perfusion pump was stopped and $0.5 \mathrm{~mL}$ of fluorescein solution $(0.10 \%)$ was injected slowly through a sidearm port connected to the aortic cannula. The dye was passed through the heart for $10 \mathrm{sec}$ to ensure its uniform tissue distribution. The presence of fluorescein was used to demarcate the tissue that was not subjected to regional ischemia, as opposed to the risk region. The heart was removed from the perfusion apparatus and cut into two transverse sections at right angles to the vertical axis. The right ventricle, apex, and atrial tissue were discarded. The areas of the normal left ventricle nonrisk region, area at risk, and infarct region were determined using the technique reported by both and coworkers [29]. Total area at risk was expressed as the percentage of the left ventricle.

\subsubsection{Second Stage}

Effect Induced by Testosterone and Its Derivative on Perfusion Pressure. Changes in perfusion pressure as a consequence of increases in time ( 3 to $18 \mathrm{~min}$ ) in the absence (control) or presence of testosterone and its derivative at a concentration of $0.001 \mathrm{nM}$ were determined. The effects were obtained in isolated hearts perfused at a constant flow rate of $10 \mathrm{~mL} / \mathrm{min}$.

Evaluation of Effects Exerted by the Testosterone and Its Derivative on Coronary Resistance. The coronary resistance in the absence (control) or presence of testosterone and its derivative at a concentration of $0.001 \mathrm{nM}$ was evaluated. It is noteworthy that Coronary resistance was calculated as the ratio of perfusión pressure at coronary flow assayed $(10 \mathrm{~mL} / \mathrm{min})$.

\subsubsection{Third Stage}

Effects Induced by Testosterone and Its Derivative on Left Ventricular Pressure through Androgen Receptors. Intracoronary boluses $(50 \mu \mathrm{L})$ of testosterone and its derivative $(0.001$ to $100 \mathrm{nM}$ ) were administered and the corresponding effect on the left ventricular pressure was determined. The doseresponse curve (control) was repeated in the presence of flutamide at a concentration of $1 \mathrm{nM}$ (duration of preincubation with flutamide was by a 10 min equilibration period).

Effects Induced by the Testosterone Derivative on Left Ventricular Pressure through $\beta_{1}$-Adrenergic Receptor. Intracoronary boluses $(50 \mu \mathrm{L})$ of the testosterone derivative $(0.001$ to $100 \mathrm{nM}$ ) were administered and the corresponding effect on the left ventricular pressure was determined. The doseresponse curve (control) was repeated in the presence of metoprolol at a concentration of $1 \mathrm{nM}$ (duration of preincubation with metoprolol was by a 10 min equilibration period).

Effects Exerted by the Testosterone Derivative on Left Ventricular Pressure through $\alpha_{1}$-Adrenergic Receptor. Intracoronary boluses $(50 \mu \mathrm{L})$ of the testosterone derivative $(0.001$ to $100 \mathrm{nM}$ ) were administered and the corresponding effect on the left ventricular pressure was determined. The doseresponse curve (control) was repeated in the presence of prazosin a concentration of $1 \mathrm{nM}$ (duration of preincubation with prazosin was by a 10 min equilibration period).

Effects of the Testosterone Derivative on Left Ventricular Pressure through the Calcium Channel. Intracoronary boluses $(50 \mu \mathrm{L})$ of the testosterone derivative [0.001 to $100 \mathrm{nM}]$ were administered and the corresponding effect on the left ventricular pressure was evaluated. The dose-response curve (control) was repeated in the presence of nifedipine at a concentration of $1 \mathrm{nM}$ (duration of the preincubation with nifedipine was for a period of $10 \mathrm{~min}$ ).

Effect Exerted by the Testosterone Derivative on Left Ventricular Pressure in the Presence of Indomethacin. The boluses $(50 \mu \mathrm{L})$ of the testosterone derivative [0.001 to $100 \mathrm{nM}]$ were administered and the corresponding effect on the left ventricular pressure was evaluated. The bolus injection administered was done in the point of cannulation. The dose-response curve (control) was repeated in the presence of indomethacin at a concentration of $1 \mathrm{nM}$ (duration of the preincubation with indomethacin was for a period of $10 \mathrm{~min}$ ). 

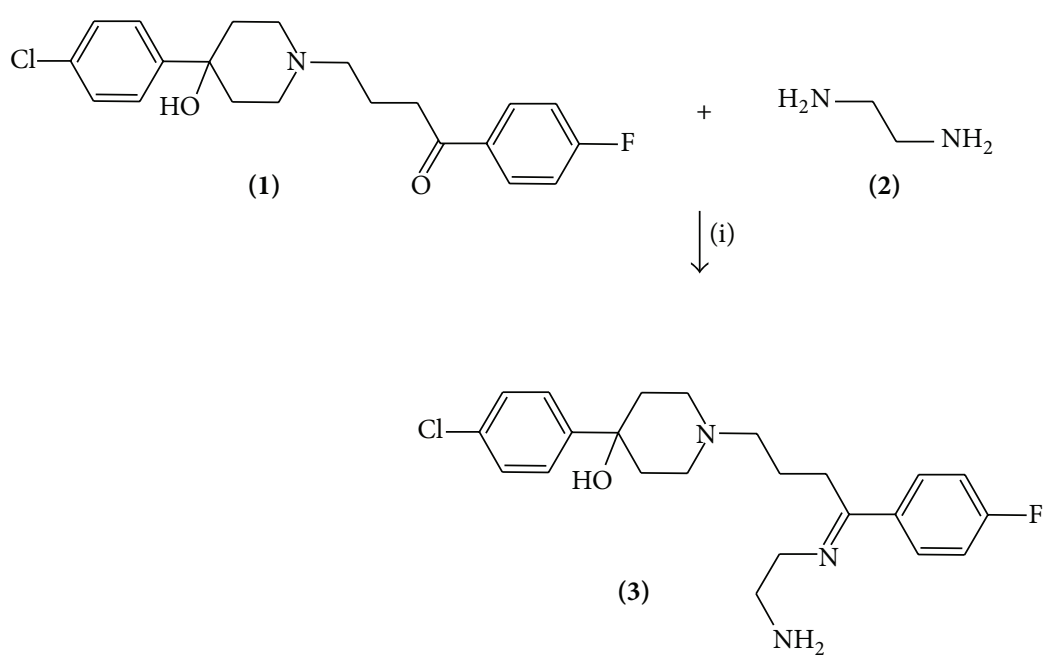

FIGURE 1: Synthesis of 1-[4-(2-amino-ethylimino)-4-(4-fluoro-cyclohexyl)-butyl]-4-(4-chloro-phenyl)-piperidin-4-ol (3). Reaction of haloperidol with ethylenediamine using boric acid as catalyst (i) to form the compound 3.

Effects of the Testosterone Derivative on Left Ventricular Pressure through the TXA 2 Receptor Activation. Intracoronary boluses $(50 \mu \mathrm{L})$ of the testosterone derivative [0.001 to $100 \mathrm{nM}$ ] were administered and the corresponding effect on the left ventricular pressure was evaluated. The doseresponse curve (control) was repeated in the presence of PINANE $\mathrm{TXA}_{2}$ at a concentration of $1 \mathrm{nM}$ (duration of the preincubation with PINANE TXA 2 was for a period of $10 \mathrm{~min})$.

\subsubsection{Fourth Stage}

Activity Induced by Indomethacin and PINANE TXA $A_{2}$ in Presence $y$ Absence of the Testosterone Derivative Using an Ischemia/Reperfusion Model. After 15 minutes of equilibration time, the hearts were subjected to ischemia for 30 minutes by turning off the perfusion system [29]. After this period, the system was restarted and the hearts were reperfused by 30 minutes with Krebs-Henseleit solution. The hearts were randomly divided into 3 major treatment groups with $n=6$.

Group I. Hearts were subjected to ischemia/reperfusion but received vehicle only (Krebs-Henseleit solution).

Group II. Hearts were subjected to ischemia/reperfusion and treated with the testosterone derivative at a dose of $0.001 \mathrm{nM}$ before ischemia period (for 10 minutes) and during the entire period of reperfusion.

Group III. Hearts were subjected to ischemia/reperfusion and treated with testosterone derivative at a dose of $0.001 \mathrm{nM}$ before ischemia period (for 10 minutes) and during the entire period of reperfusion. The dose-response curve (control) was repeated in the presence of indomethacin at a concentration of $1 \mathrm{nM}$.

Group IV. Hearts were subjected to ischemia/reperfusion and treated with testosterone derivative at a dose of $0.001 \mathrm{nM}$ before ischemia period (for 10 minutes) and during the entire period of reperfusion. The dose-response curve (control) was repeated in the presence of PINANE TXA 2 at a concentration of $1 \mathrm{nM}$.

Group V. Hearts were subjected to ischemia/reperfusion and treated with the indomethacin at a dose of $0.001 \mathrm{nM}$ before ischemia period (for 10 minutes) and during the entire period of reperfusion.

Group VI. Hearts were subjected to ischemia/reperfusion and treated with the PINANE TXA 2 at a dose of $0.001 \mathrm{nM}$ before ischemia period (for 10 minutes) and during the entire period of reperfusion.

The areas of the normal left ventricle nonrisk region, area at risk, and infarct region were determined using the technique reported by both and coworkers [29]. Total area at risk was expressed as the percentage of the left ventricle.

2.7. Statistical Analysis. The obtained values are expressed as average $\pm \mathrm{SE}$. The data obtained were put under analysis of variance (ANOVA) with the Bonferroni correction factor using the SPSS 12.0 program [30]. The differences were considered significant when $P$ was equal or smaller than 0.05 .

\section{Results}

The yielding of compound 3 (Figure 1) was of $85 \%$ with melting point of $78-80^{\circ} \mathrm{C}$. In addition, the spectroscopic analyses showed signals for IR $\left(V_{\max }, \mathrm{cm}^{-1}\right)$ at 3412,3382 , and 3330. The chemical shifts of the spectroscopic analyses of ${ }^{1} \mathrm{H}$ NMR and ${ }^{13} \mathrm{C}$ NMR for compound 3 are showed in Tables 1 and 2. Finally, the results of mass spectroscopy (MS) $(70 \mathrm{eV})$ are shown, $m / z 417.10\left[\mathrm{M}^{+}, 10\right]$. Additionally, the elementary analysis data for compound $3\left(\mathrm{C}_{23} \mathrm{H}_{29} \mathrm{ClFN}_{3} \mathrm{O}\right)$ was calculated (C, 66.10; H, 6.99; Cl, 8.48; F, 4.55; N, 10.05; O, 3.83) and found (C, 66.08; H, 6.97).

Furthermore, other results (Figure 2) showed a yielding of $64 \%$ and a melting point of $170-172^{\circ} \mathrm{C}$, for the testosterone 


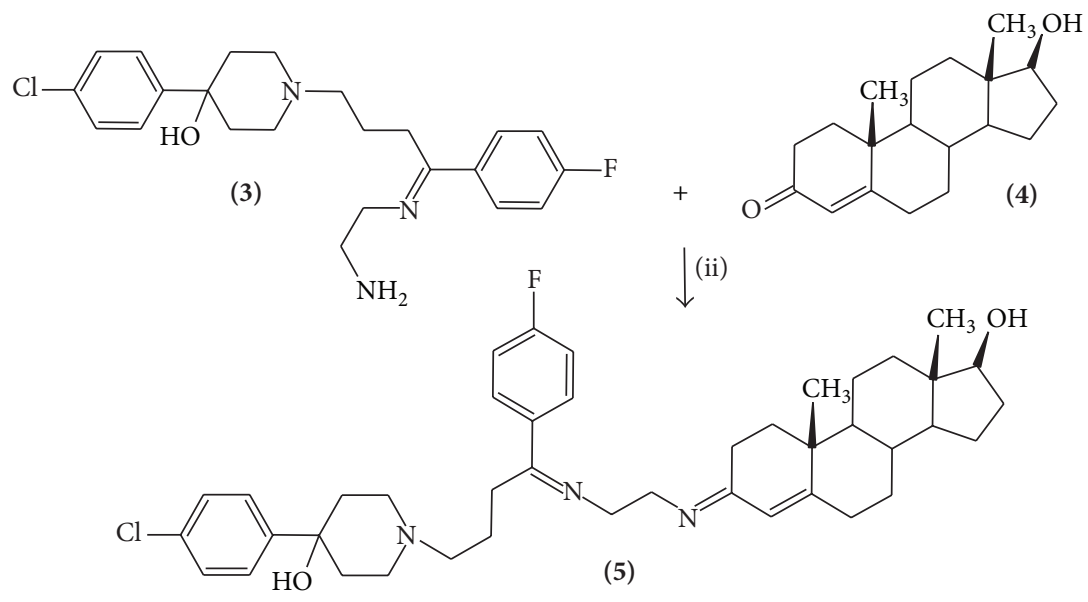

Figure 2: Synthesis of $\quad 4$-(4-chloro-phenyl)-1-\{4-(4-fluoro-phenyl)-4-[2-(17-hydroxy-10,13-dimethyl-1,2,6,7,8,9,10,11,12,13,14,15,16,17tetradecahydro-cyclopenta[a]phenan thren-3-ylideneamino)-ethylimino]-butyl\}-piperidin-4-ol (5). Reaction of 1-[4-(2-amino-ethylimino)4-(4-fluoro-cyclohexyl)-butyl]-4-(chloro-phenyl)-piperidin-4-ol (3) with testosterone (2) to form the compound 3. (ii) = boric acid.

TABle 1: ${ }^{1} \mathrm{H}$ NMR $\left(300 \mathrm{MHz}, \mathrm{CDCl}_{3}\right)$ data for the haloperidol derivative (compound 3 ).

$1.52-1.69(\mathrm{~m}, 4 \mathrm{H}), 1.71(\mathrm{t}, 2 \mathrm{H}, J=6.9 \mathrm{~Hz}), 2.31(\mathrm{t}, 2 \mathrm{H}, J=6.9 \mathrm{~Hz})$, $2.50(\mathrm{t}, 2 \mathrm{H}, J=6.9 \mathrm{~Hz}), 2.753 .03(\mathrm{~m}, 4 \mathrm{H}), 3.08(\mathrm{t}, 2 \mathrm{H}, J=6.5 \mathrm{~Hz})$, $3.51(\mathrm{t}, 2 \mathrm{H}, J=6.5 \mathrm{~Hz}), 4.63(\mathrm{~s}, 3 \mathrm{H}), 7.06-8.10(\mathrm{~m}, 8 \mathrm{H}) \mathrm{ppm}$.

TABle 2: ${ }^{13} \mathrm{C}$ NMR $\left(300 \mathrm{MHz}, \mathrm{CDCl}_{3}\right.$ ) data for the haloperidol derivative (compound 3 ).

$26.15,28.47,38.40,41.02,47.04,53.63,54.09,70.12,115.08,126.80$, $128.64,129.15,134.40,136.17,145.22,162.11,163.30 \mathrm{ppm}$.

derivative (compound 5). Additionally, the spectroscopic analyses showed signals for IR $\left(V_{\max }, \mathrm{cm}^{-1}\right)$ at $3410,3,338$, and 2912. The chemical shifts of the spectroscopic analyses of ${ }^{1} \mathrm{H}$ NMR and ${ }^{13} \mathrm{C}$ NMR for the testosterone derivative are showed in Tables 3 and 4 . Finally, the results of mass spectroscopy (MS) $(70 \mathrm{eV})$ are shown, $m / z 687.32\left[\mathrm{M}^{+}, 12\right]$. Additionally, the elementary analysis data for compound $\mathbf{5}$ $\left(\mathrm{C}_{42} \mathrm{H}_{55} \mathrm{ClFN}_{3} \mathrm{O}_{2}\right)$ was calculated $(\mathrm{C}, 73.28 ; \mathrm{H}, 8.05 ; \mathrm{Cl}, 5.15$; $\mathrm{F}, 2.76 ; \mathrm{N}, 6.10 ; \mathrm{O}, 4.65)$ and found $(\mathrm{C}, 73.26 ; \mathrm{H}, 8.04)$.

\subsection{Biological Evaluation}

\subsubsection{First Stage}

Activity Induced the Testosterone Derivative Using an Ischemia/Reperfusion Model. The results (Figure 3) showed that the testosterone derivative significantly reduced $(P=0.06)$ infarct size (expressed as a percentage of the area at risk) compared with both testosterone and vehicle-treated hearts.

3.1.2. Second Stage. In this study, the activity induced by the testosterone and its derivative on perfusion pressure and coronary resistance in the isolated rat heart was evaluated.
TABle 3: ${ }^{1} \mathrm{H}$ NMR $\left(300 \mathrm{MHz}, \mathrm{CDCl}_{3}\right)$ data for the testosterone derivative (compound 5).

$0.80(\mathrm{~s}, 3 \mathrm{H}), 0.96-1.02(\mathrm{~m}, 3 \mathrm{H}), 1.05(\mathrm{~s}, 3 \mathrm{H}), 1.08-1.48(\mathrm{~m}, 6 \mathrm{H})$ $1.54(\mathrm{~m}, 2 \mathrm{H}), 1.58-1.62(\mathrm{~m}, 3 \mathrm{H}), 1.64(\mathrm{~m}, 2 \mathrm{H}), 1.69(\mathrm{~m}, 1 \mathrm{H}), 1.74(\mathrm{t}$, $2 \mathrm{H}, J=6.54), 1.86-2.38(\mathrm{~m}, 7 \mathrm{H}), 2.42(\mathrm{t}, 2 \mathrm{H}, J=6.54), 2.54(\mathrm{t}$, $2 \mathrm{H}, J=6.54), 2.78-3.00(\mathrm{~m}, 4 \mathrm{H}), 3.60(\mathrm{~m}, 1 \mathrm{H}), 3.70(\mathrm{t}, 2 \mathrm{H}$, $J=6.54), 3.80(\mathrm{t}, 2 \mathrm{H}, J=6.54), 4.74($ broad, $2 \mathrm{H}), 5.86(\mathrm{~m}, 1 \mathrm{H})$, 6.90-8.10 (m, 8H) ppm.

TAble $4:{ }^{13} \mathrm{C}$ NMR $\left(300 \mathrm{MHz}, \mathrm{CDCl}_{3}\right)$ data for the testosterone derivative (compound $\mathbf{5}$ ).

$11.10,17.70,21.08,23.32,26.78,28.72,30.26,30.38,31.10,31.28,31.70$, $35.20,35.34,36.66,38.30,42.80,47.04,50.20,50.56,51.70,52.40$, $54.22,70.00,80.78,115.08,115.38,126.80,128.60,129.15,136.17$, $136.72,145.18,157.40,162.12,163.84,165.82 \mathrm{ppm}$.

The results obtained (Figure 4) from changes in perfusion pressure as a consequence of increases in the time (3-18 $\mathrm{min}$ ) showed that the testosterone derivative at a dose of $0.001 \mathrm{nM}$ significantly increases the perfusion pressure $(\mathbf{P}=0.05)$ in comparison with the control conditions and testosterone $[0.001 \mathrm{nM}]$. Other result (Figure 5) showed that coronary resistance, calculated as the ratio of perfusion pressure at coronary flow assayed $(10 \mathrm{~mL} / \mathrm{min})$, was significantly higher $(\mathbf{P}=0.05)$ in the presence of steroid derivative $[0.001 \mathrm{nM}]$ than in control conditions and testosterone $[0.001 \mathrm{nM}]$.

3.1.3. Third Stage. Figure 6 showed that the testosterone and its derivative induce an increase on left ventricular pressure in a dose-dependent manner [0.001 to $100 \mathrm{nM}$ ]; however, only the effect exerted by testosterone was significantly inhibited by flutamide at a dose of $1 \mathrm{nM}(\mathbf{P}=0.06)$.

On the other hand, other experiments showed that the testosterone derivative increased left ventricular pressure in a dose-dependent manner [0.001 to $100 \mathrm{nM}$ ] and this effect was not inhibited in presence of prazosin or metoprolol (Figure 7) 


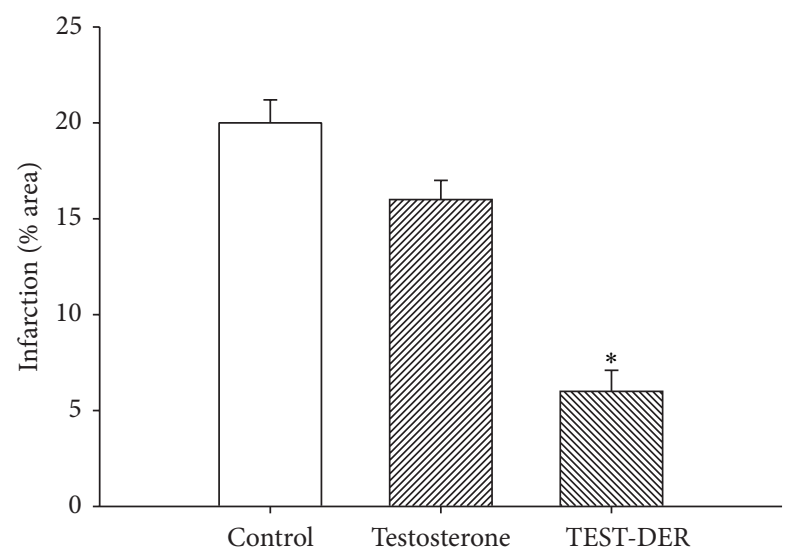

FIGURE 3: Effect exerted by the testosterone and its derivative (TESTDER) on cardiac ischemia/reperfusion. The results showed that the testosterone derivative significantly reduced infarct size expressed as a percentage of the area at risk compared with testosterone and the vehicle-treated hearts $(\mathbf{P}=0.06)$. Each bar represents the mean \pm SE of 9 experiments.

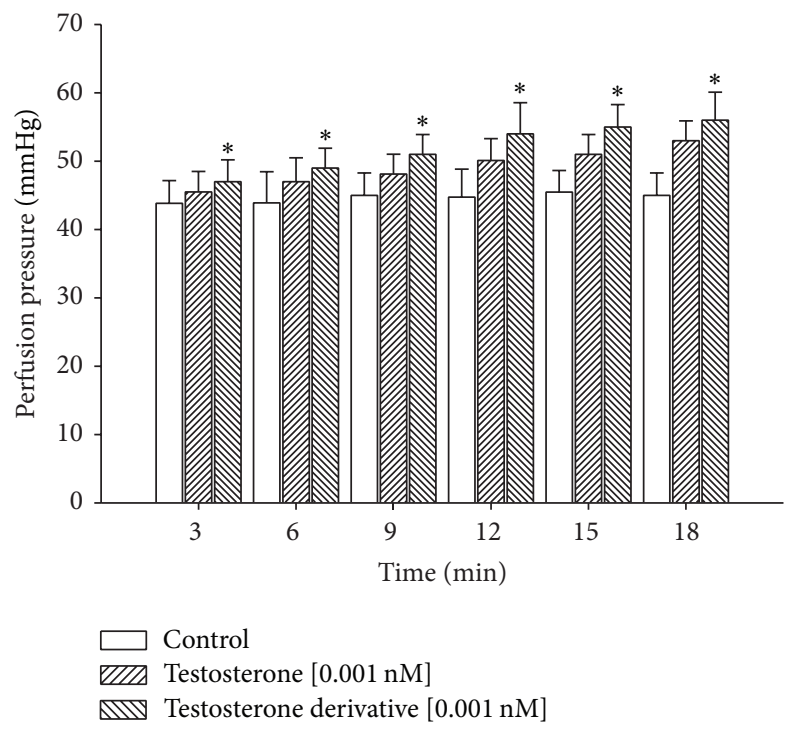

Figure 4: Effect induced by the testosterone and its derivative on perfusion pressure. The results showed that the testosterone derivative significantly increases perfusion pressure $(\mathbf{P}=0.05)$ through time in comparison with the control conditions and testosterone. Each bar represents the mean \pm SE of 9 experiments.

at a concentration of $1 \mathrm{nM}$. Additionally, other results indicate that effect induced by the testosterone derivative on left ventricular pressure (Figure 8) in presence of nifedipine at a concentration of $1 \mathrm{nM}$ was not blocked. Finally, other results (Figure 9) indicate that activity exerted by the testosterone derivative [ 0.001 to $100 \mathrm{nM}$ ] on left ventricular of testosterone was significantly blocked in presence of indomethacin $(\mathbf{P}=$ $0.05)$ and PINAME TXA $2(\mathbf{P}=0.05)$ at a dose of $1 \mathrm{nM}$.

3.1.4. Fourth Stage. The results (Figure 10) showed that the testosterone derivative significantly reduced $(P=0.06)$

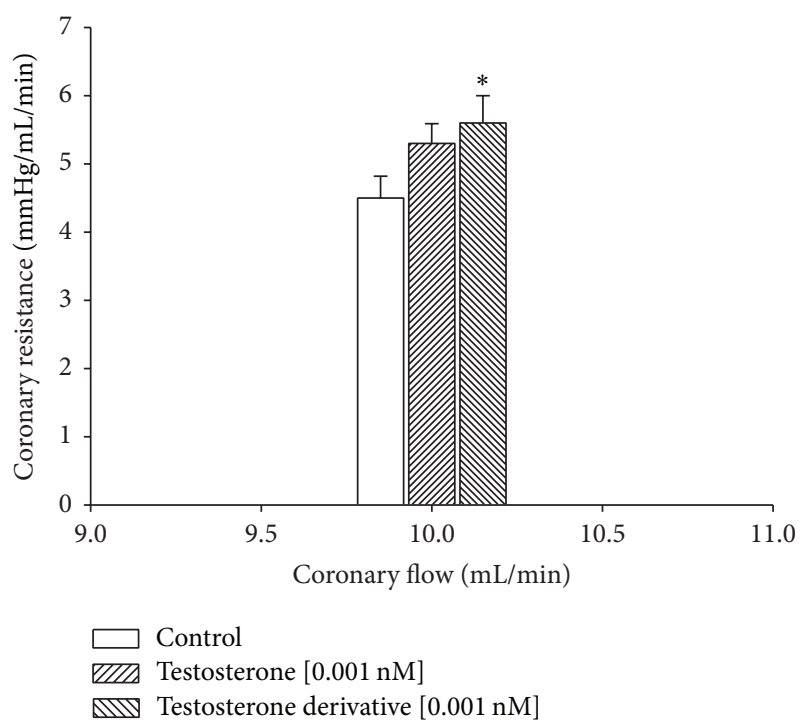

FIGURE 5: Activity exerted by the testosterone derivative and its derivative on coronary resistance. The results show that coronary resistance was higher $(\mathbf{P}=0.05)$ in the presence of the testosterone derivative in comparison with the control conditions and testosterone. Each bar represents the mean \pm SE of 9 experiments.

infarct size (expressed as a percentage of the area at risk) compared with vehicle-treated hearts. However, this effect was partially blocked by indomethacin and PINANE $\mathrm{TXA}_{2}$. Other data indicate that Indomethacin significantly decreased infarct size $(P=0.05)$ in comparison with testosterone derivative, PINANE TXA $\mathrm{T}_{2}$, and vehicle-treated hearts.

\section{Discussion}

4.1. Chemical Synthesis. There are many procedures for preparation of several androgen derivatives; nevertheless, despite its wide scope, have some drawbacks; for example, several agents used have limited stability and their preparation requires special conditions [31,32]. Analyzing these data, we report a straightforward route for synthesis of an androgen derivative using some strategies. The first stage was achieved by the synthesis of 1-[4-(2-amino-ethylimino)-4-(4-fluorocyclohexyl)-butyl]-4-(4-chloro-phenyl)-piperidin-4-ol (3) which has an imine group (Schiff base) involved in their chemical structure (Figure 1). It is noteworthy that there are several procedures for the synthesis of imine groups which are described in the literature [33,34]. However, in this study, the synthesis of compound $\mathbf{3}$ was developed by the reaction of haloperidol with ethylenediamine using boric acid as catalyst to form 3 . The structure of compound 3 was confirmed using IR and NMR spectroscopy (Tables 1 and 2). The IR spectra contained characteristic vibrations at 3412 for hydroxyl group; at 3382 for amino group; at 3330 for imino groups, and 2910 piperidine ring. The ${ }^{1} \mathrm{H}$ NMR spectrum of 3 shows signals at $1.52-1.69 \mathrm{ppm}$ for piperidine ring; at $1.71-2.50 \mathrm{ppm}$ for methylene groups bound to both imino and piperidine groups; at $2.75-3.03 \mathrm{ppm}$ for piperidine 


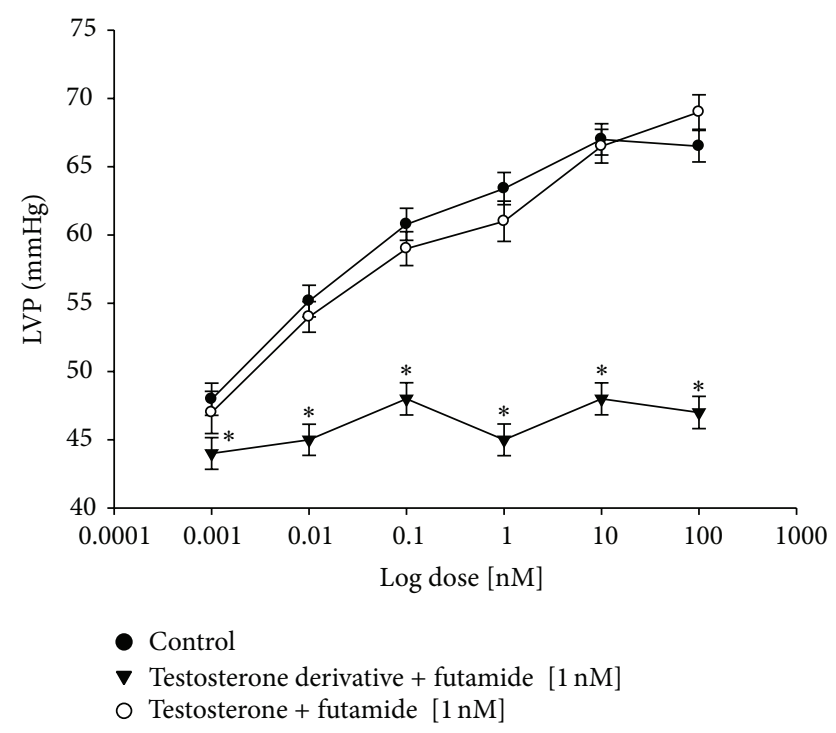

FIGURE 6: Effects induced by the testosterone and its derivative on LVP through androgen receptor. Intracoronary boluses $(50 \mu \mathrm{L})$ of the testosterone and its derivative [0.001 to $100 \mathrm{nM}$ ] were administered and the corresponding effect on the LVP was determined. The dose-response curve (control) was repeated in the presence of flutamide (duration of preincubation with flutamide was by a $10 \mathrm{~min}$ equilibration period). The results showed that only the activity exerted of testosterone on LVP was significantly inhibited $(\mathbf{P}=$ 0.06). Each bar represents the mean \pm SE of 9 experiments. LVP: left ventricular pressure.

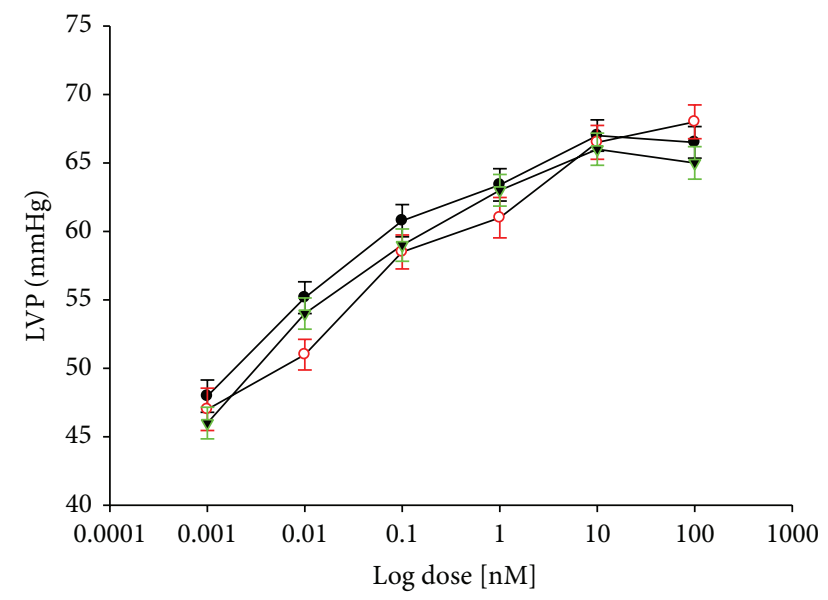

- Testosterone derivative

Testosterone derivative + metroprolol $[1 \mathrm{nM}]$

$\boldsymbol{\nabla}$ Testosterone derivative + prazosin $[1 \mathrm{nM}]$

FIGURE 7: Activity exerted by the testosterone derivative on LVP through of adrenergic receptors. Testosterone derivative [0.001 to $100 \mathrm{nM}$ ] was administered (intracoronary boluses, $50 \mu \mathrm{L}$ ) and the corresponding effect on the LVP was evaluated in the absence and presence of prazosin or metoprolol. The results showed that activity induced by the testosterone derivative on LVP was not inhibited in the presence of prazosin or metoprolol. Each bar represents the mean \pm SE of 9 experiments. LVP: left ventricular pressure.

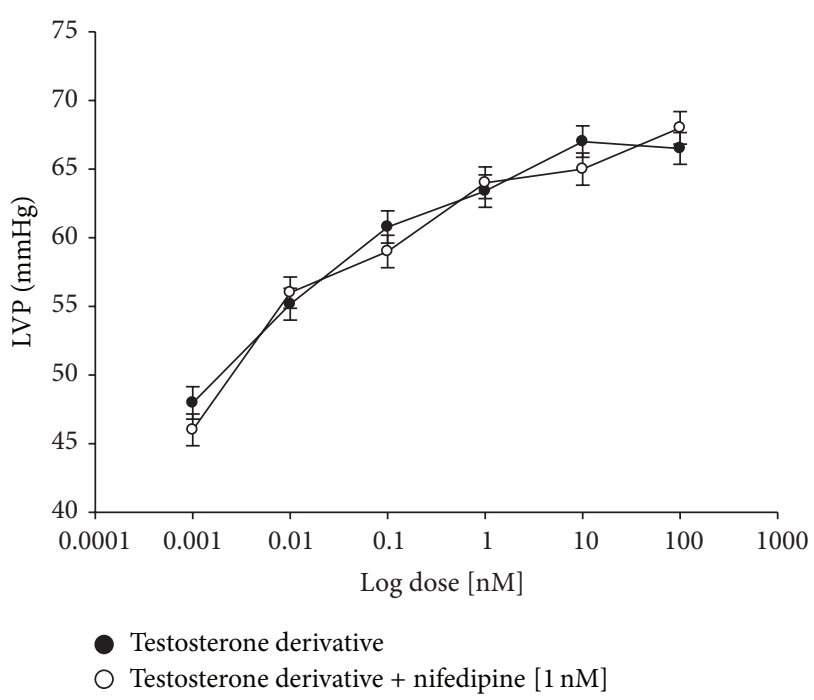

FIGURE 8: Effects induced by the testosterone derivative on LVP through calcium channel activation. Intracoronary boluses $(50 \mu \mathrm{L})$ of the testosterone derivative [ 0.001 to $100 \mathrm{nM}$ ] were administered and the corresponding effect on the LVP was determined in the absence and presence of nifedipine. The results showed that the testosterone derivative increases the LVP in a dose-dependent manner and this effect was not inhibited in the presence of nifedipine. Each bar represents the mean \pm SE of 9 experiments. LVP: left ventricular pressure.

ring; at 3.08-3.51 ppm for methylene groups bound to both imino and amino groups; at $4.63 \mathrm{ppm}$ for both hydroxyl and amino groups; at 7.06-8.10 ppm for both phenyl groups. The ${ }^{13} \mathrm{C}$ NMR spectra showed chemical shifts at 26.15, 28.47, and $53.63 \mathrm{ppm}$ for methylene groups bound to both imino and piperidine groups; at 38.40, 47.04, and $70.12 \mathrm{ppm}$ for piperidine ring; at 41.02 and 54.09 ppm for methylene groups bound to both amino and imino groups; at 115.08-145.22 and $163.30 \mathrm{ppm}$ for both phenyl groups; at $162.11 \mathrm{ppm}$ for imino group. Finally, the presence of testosterone derivative was further confirmed from mass spectrum which showed a molecular ion at $m / z 417.12$.

The second stage was achieved by the synthesis of the testosterone derivative by the reaction of compound 3 with testosterone using boric acid as catalyst to form a new imino group involved in the chemical structure of the steroid derivative. The structure of the testosterone derivative was confirmed using IR and NMR spectroscopy (Tables 3 and 4). The IR spectra contained characteristic vibrations at 3410 for hydroxyl group; at 3338 for both imino groups and 2912 piperidine ring. The ${ }^{1} \mathrm{H}$ NMR spectrum of the testosterone derivative shows signals at 0.80 and $1.05 \mathrm{ppm}$ for methyl groups bound to steroid nucleus; at 0.96-1.02, 1.08-1.48, 1.58$1.62,1.69,1.86-2.38,3.60$, and $5.86 \mathrm{ppm}$ for steroid nucleus; at $1.54,1.64$ and $2.78-3.00 \mathrm{ppm}$ for piperidine ring; at 1.74 and $2.42-2.54 \mathrm{ppm}$ for methylene groups bound to both piperidine ring and imine groups; at 3.70 and $3.803 .99 \mathrm{ppm}$ for methylene groups bound to both imino groups. Finally, two signals at $4.74 \mathrm{ppm}$ for both hydroxyl groups and at 6.90$8.10 \mathrm{ppm}$ for phenyl groups were found. 


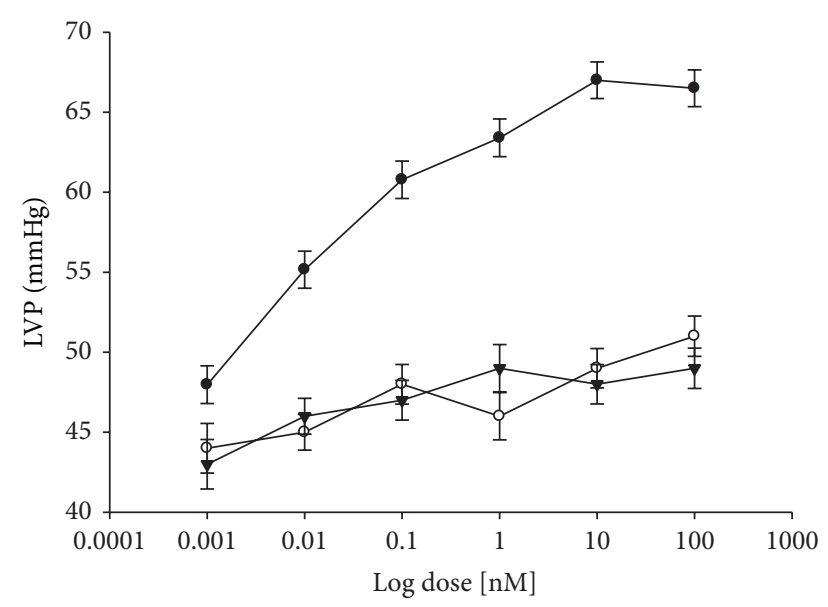

- Testosterone derivative

O Testosterone derivative + indomethacin [1 $\mathrm{nM}]$

$\nabla$ Testosterone derivative + PINAME TXA $2[1 \mathrm{nM}]$

FIGURE 9: Effects induced by the testosterone derivative on LVP through prostaglandins synthesis and thromboxane receptor. Intracoronary boluses $(50 \mu \mathrm{L})$ of the testosterone derivative [0.001 to $100 \mathrm{nM}$ ] were administered and the corresponding effect on the LVP was determined in the absence and presence of indomethacin and PINANE $\mathrm{TXA}_{2}$. The results showed that the testosterone derivative increases the LVP in a dose-dependent manner and this effect was significantly inhibited in the presence of indomethacin $(P=0.05)$ and PINANE TXA $2(P=0.05)$. Each bar represents the mean $\pm \mathrm{SE}$ of 9 experiments. LVP: left ventricular pressure.

On the other hand, the ${ }^{13} \mathrm{C}$ NMR spectra showed chemical shifts at 11.10 and $17.70 \mathrm{ppm}$ for both methyl groups bound to steroid nucleus; at 21.08-23.32, 30.26-30.66, 42.80, $50.20-50.56,80.78,115.38$, and $157.40 \mathrm{ppm}$ for steroid nucleus; at $26.78-28.72$ and $54.22 \mathrm{ppm}$ for methylene groups bound to both piperidine and imino groups; at $38.30,47.04$, and $70.00 \mathrm{ppm}$ for piperidine ring; at $51.70-52.40 \mathrm{ppm}$ for methylene groups bound to both imino groups; at 115.06, 126.80, 136.72 , and $163.84 \mathrm{ppm}$ for phenyl group bound to imino group; at 128.60-136.17 and $145.18 \mathrm{ppm}$ for phenyl group bound to piperidine ring; at 162.12 and $165.82 \mathrm{ppm}$ for both imino groups. Finally, the presence of testosterone derivative was further confirmed from mass spectrum which showed a molecular ion at $m / z 687.36$.

4.2. Biological Evaluation. In this study, the activity of the testosterone derivative on myocardial injury using an ischaemia/reperfusion model was evaluated. The results showed that the testosterone derivative significantly reduced infarct size (expressed as a percentage of the area at risk) compared with both testosterone and vehicle-treated hearts. This effect can be conditioned by changes in the chemical structure of testosterone which may consequently bring activation of some biological structures (e.g., ionic channels or specific receptors) involved in the endothelium of coronary artery [35] or by the influence exerted by the testosterone derivative on blood pressure which consequently bring reduction in the infarct size and decrease the myocardial

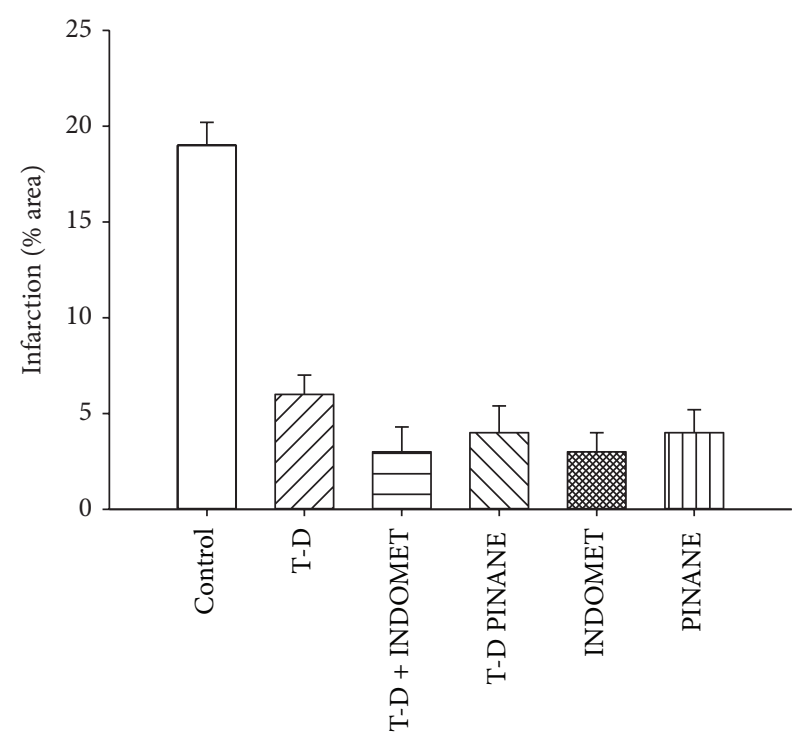

FIGURE 10: Effect exerted by indomethacin (INDOMET) and PINANE TXA2 (PINANE) in presence and absence of testosterone derivative (T-D) on cardiac ischemia/reperfusion.The results showed that T-D significantly reduced infarct size expressed as a percentage of the area at risk compared with testosterone and the vehicle-treated hearts $(\mathbf{P}=0.06)$. However, this effect was partially blocked by INDOMET and PINANE. Other data indicate that INDOMET significantly decreased infarct size $(P=0.05)$ in comparison with PINANE. Each bar represents the mean \pm SE of 6 experiments.

injury after ischemia/reperfusion similar to other reports for other types of steroids [36]. To assess these hypotheses, the effect induced by the testosterone and its derivative on blood vessel capacity and coronary resistance, translated as changes in perfusion pressure, was evaluated in an isolated rat heart model. The experimental results showed that the testosterone derivative significantly increases the perfusion pressure over time (3-18 min) compared with testosterone and the control conditions. These data suggest that activity induced by the testosterone derivative on perfusion pressure could modify vascular tone and coronary resistance of heart. Therefore, in this study, the activity exerted by testosterone and its derivative on coronary resistance was evaluated. The results indicate that coronary resistance was increased in presence of the steroid derivative. These data suggest that the testosterone derivative exerts effects on vascular tone through the generation or activation of vasoactive substances such as intracellular calcium. This phenomenon is similar to the activity exerted by other compounds such as the carbamazepine-alkyne derivative [37].

In order to characterize the molecular mechanism of this phenomenon and analyze the reports of some investigations which indicate that testosterone induces its effect on blood pressure via activation of the androgen receptor [38], we used flutamide (androgen-receptor blocker) to determine if the effects of testosterone and its derivative on perfusion pressure were via the androgen receptor. Our results showed that only the effect of testosterone was significantly inhibited 
in presence of flutamide; however, the testosterone derivative was not inhibited by the androgen-receptor blocker, suggesting that the molecular mechanism for the testosterone derivative is not via the androgenic receptor. In search of molecular mechanism involved in the activity of the testosterone derivative and analyzing a study which indicates that some androgens such as dehydroisoandrosterone 3-sulfate stimulate catecholamines production and this phenomenon may induce a positive inotropic effect $[39,40]$ which has an important role in the development or maintenance of elevated blood pressure [41]. For this reason, in this study, the effect exerted by the testosterone derivative on left ventricular pressure was evaluated in the absence or presence of prazosin or metoprolol. The experimental results showed that the effect induced by the testosterone derivative was not inhibited in the presence of these compounds. These data indicated that the molecular mechanism involved in the activity of testosterone derivative is not via adrenergic system.

Analyzing the results obtained and other reports which indicate that some steroid derivatives can induce changes on blood pressure by increasing calcium levels [42]; in this study, we also considered validating the effect induced by the testosterone derivative on left ventricular pressure via the calcium channels activation using as pharmacological tool to nifedipine. The results showed that the effect induced by the testosterone derivative was not inhibited in the presence of nifedipine. These results indicate that activity of the testosterone derivative was not through calcium channels activation.

On the other hand, in the search of the molecular mechanism involved in effect induced by the testosterone derivative on left ventricular pressure and analyzing previous reports, which indicate that some steroids exert its effect on left ventricular pressure via prostaglandins synthesis [43]. In this sense, other alternative experiments were conducted to evaluate the possibility that the activities exerted by the testosterone derivative on left ventricular pressure involve stimulation and secretion of prostaglandins using as pharmacological tool indomethacin. The results showed that effect induced by the testosterone derivative on left ventricular pressure was blocked by indomethacin. These results indicate that the molecular mechanism involved in the effect exerted by the testosterone derivative was via prostaglandins. To assess whether the activity exercised by the derivative of testosterone on left ventricular pressure involves the activation or release of a specific prostaglandin such as thromboxane $\mathrm{A}_{2}$ as $\left(\mathrm{TXA}_{2}\right)$ which is a substance that induces a vasoconstriction effect in heart [44]. In addition, it is important to mention that $\mathrm{TXA}_{2}$ has been found into the coronary circulation in patients with ischemic heart disease [45]. Therefore, in this study, other experiments were conducted using thromboxane receptor antagonist (PINANE $\mathrm{TXA}_{2}$ ) as pharmacological tool. The results indicate that effect exerted by the testosterone derivative was significantly inhibited by PINANE TXA2; these experimental data suggest that activity of the testosterone derivative on left ventricular pressure could be through receptor thromboxane A2 activation which consequently brings decrease in the ischemia/reperfusion injury. To assess this hypothesis, several experiments were conducted to evaluate the activity of indomethacin and PINANE $\mathrm{TXA}_{2}$ on ischemia/reperfusion injury in the presence or absence of the testosterone derivative. The results showed that effect exerted by steroid derivative on ischemia/reperfusion injury was inhibited partiality with indomethacin and PINANE TXA 2 . Additionally, other data showed that beneficial effects on ischemia/reperfusion injury induced by indomethacin and PINANE TXA $\mathrm{T}_{2}$ were higher in comparison with testosterone derivative. All these data indicate that; (1) indomethacin blocked the activity of COX and this phenomenon consequently bring inhibition of synthesis or release to two prostaglandins such as PGI2 (prostaciclin) and TXA2 (tromboxane $\mathrm{A}_{2}$ ) which exert effects on ischemia/reperfusion injury such as happening in other types of studies [7-9, 14]; (2) the testosterone derivative decreases the ischemia/reperfusion injury through thromboxane receptor activation; (3) the steroid derivative could induce an imbalance in the relation of $\mathrm{PGI}_{2} / \mathrm{TXA}_{2}$ which may consequently bring changes in the metabolism of myocardium and induce a decrease of the ischemia/reperfusion injury.

\section{Conclusions}

The testosterone derivative is a particularly interesting drug, because the activity induced for this compound on ischemia/reperfusion injury involves a molecular mechanism different in comparison with other drugs. This phenomenon may constitute a novel therapy for ischemia/reperfusion injury.

\section{Conflict of Interests}

The authors declare that this paper does not have any conflict of interests (political, personal, religious, ideological, academic, intellectual, commercial, or otherwise) regarding the publication of the paper.

\section{References}

[1] S. Yusuf, S. Hawken, and S. Ounpuu, "Effect of potentially modifiable risk factors associated with myocardial infarction in 52 countries (the INTERHEART study): case-control study," The Lancet, vol. 366, no. 9497, pp. 1640-1649, 2005.

[2] K. Thygesen, J. S. Alpert, and H. D. White, "Universal definition of myocardial infarction," Journal of the American College of Cardiology, vol. 50, no. 22, pp. 2173-2195, 2007.

[3] M. A. Pfeffer, "Left ventricular remodeling after acute myocardial infarction," Annual Review of Medicine, vol. 46, pp. 455466, 1995.

[4] P. Zhai, T. E. Eurell, R. Cotthaus, E. H. Jeffery, J. M. Bahr, and D. R. Gross, "Effect of estrogen on global myocardial ischemiareperfusion injury in female rats," The American Journal of Physiology-Heart and Circulatory Physiology, vol. 279, no. 6, pp. H2766-H2775, 2000.

[5] H. Yadav, M. Singhg, P. Sharma, D. Mittal, T. Behl, and A. Pal, "Possible role of cyclooxygenase-2 in remote aortic preconditioning induced cardioprotection in rat heart," Pharmacologia, vol. 3, no. 1, pp. 1-8, 2012. 
[6] K. Shinmura, R. Bolli, S. Liu et al., "Aldose reductase is an obligatory mediator of the late phase of ischemic preconditioning," Circulation Research, vol. 91, no. 3, pp. 240-246, 2002.

[7] L. Calabresi, G. Rossoni, M. Gomaraschi, F. Sisto, F. Berti, and G. Franceschini, "High-density lipoproteins protect isolated rat hearts from ischemia-reperfusion injury by reducing cardiac tumor necrosis factor- $\alpha$ content and enhancing prostaglandin release," Circulation Research, vol. 92, no. 3, pp. 330-337, 2003.

[8] M. G. W. Camitta, S. A. Gabel, P. Chulada et al., "Cyclooxygenase-1 and -2 knockout mice demonstrate increased cardiac ischemia/reperfusion injury but are protected by acute preconditioning," Circulation, vol. 104, no. 20, pp. 2453-2458, 2001.

[9] R. Bolli, K. Shinmura, X. Tang et al., "Discovery of a new function of cyclooxygenase (COX)-2: COX-2 is a cardioprotective protein that alleviates ischemia/reperfusion injury and mediates the late phase of preconditioning," Cardiovascular Research, vol. 55, no. 3, pp. 506-519, 2002.

[10] L. Khalaj, H. Peirovi, F. Khodagholi, A. Abdi, L. Dargahi, and A. Ahmadiani, "Acute $17 \beta$-estradiol pretreatment protects against abdominal aortic occlusion induced spinal cord ischemicreperfusion injury," Neurochemical Research, vol. 36, no. 2, pp. 268-280.

[11] X. Song, G. Li, J. Vaage, and G. Valen, "Effects of sex, gonadectomy, and oestrogen substitution on ischaemic preconditioning and ischaemia-reperfusion injury in mice," Acta Physiologica Scandinavica, vol. 177, no. 4, pp. 459-466, 2003.

[12] M. A. Cavasin, S. S. Sankey, A. Yu, S. Menon, and X. Yang, "Estrogen and testosterone have opposing effects on chronic cardiac remodeling and function in mice with myocardial infarction," The American Journal of Physiology-Heart and Circulatory Physiology, vol. 284, no. 5, pp. H1560-H1569, 2003.

[13] J. W. Horton, D. J. White, and D. L. Maass, "Gender-related differences in myocardial inflammatory and contractile responses to major burn trauma," The American Journal of PhysiologyHeart and Circulatory Physiology, vol. 286, no. 1, pp. H202H213, 2004.

[14] E. A. Booth, R. R. Flint, K. L. Lucas, A. K. Knittel, and B. R. Lucchesi, "Estrogen protects the heart from ischemia-reperfusion injury via COX-2-derived PGI2," Journal of Cardiovascular Pharmacology, vol. 52, no. 3, pp. 228-235, 2008.

[15] F. Callies, H. Strömer, R. H. G. Schwinger et al., "Administration of testosterone is associated with a reduced susceptibility to myocardial ischemia," Endocrinology, vol. 144, no. 10, pp. 44784483, 2003.

[16] M. Wang, Y. Wang, A. Abarbanell et al., "Both endogenous and exogenous testosterone decrease myocardial STAT3 activation and SOCS3 expression after acute ischemia and reperfusion," Surgery, vol. 146, no. 2, pp. 138-144, 2009.

[17] C. Huang, H. Gu, W. Zhang, J. L. Herrmann, and M. Wang, "Testosterone-down-regulated akt pathway during cardiac ischemia/reperfusion: a mechanism involving BAD, Bcl-2 and FOXO3a," Journal of Surgical Research, vol. 164, no. 1, pp. el-el1, 2010.

[18] D. E. Remmers, W. G. Cioffi, K. I. Bland, P. Wang, M. K. Angele, and I. H. Chaudry, "Testosterone: the crucial hormone responsible for depressing myocardial function in males after trauma-hemorrhage," Annals of Surgery, vol. 227, no. 6, pp. 790799, 1998.

[19] D. E. Remmers, P. Wang, W. G. Cioffi, K. I. Bland, and I. H. Chaudry, "Testosterone receptor blockade after traumahemorrhage improves cardiac and hepatic functions in males,"
The American Journal of Physiology-Heart and Circulatory Physiology, vol. 273, no. 6, pp. H2919-H2925, 1997.

[20] E. F. du Toit, E. Rossouw, J. van Rooyen, and A. Lochner, "Proposed mechanisms for the anabolic steroid-induced increase in myocardial susceptibility to ischaemia/reperfusion injury," Cardiovascular Journal of South Africa, vol. 16, no. 1, pp. 21-28, 2005.

[21] A. Vannay, A. Fekete, R. Langer et al., "Dehydroepiandrosterone pretreatment alters the ischaemia/reperfusion-induced VEGF, IL-1 and IL-6 gene expression in acute renal failure," Kidney and Blood Pressure Research, vol. 32, no. 3, pp. 175-184, 2009.

[22] J. Simard, I. Luthy, J. Guay, A. Bélanger, and F. Labrie, "Characteristics of interaction of the antiandrogen flutamide with the androgen receptor in various target tissues," Molecular and Cellular Endocrinology, vol. 44, no. 3, pp. 261-270, 1986.

[23] R. M. Graham, H. F. Oates, L. M. Stoker, and G. S. Stokes, "Alpha blocking action of the antihypertensive agent, prazosin," Journal of Pharmacology and Experimental Therapeutics, vol. 201, no. 3, pp. 747-752, 1977.

[24] C. Bengtsson, G. Johnsson, and C. G. Regardh, "Plasma levels and effects of metoprolol on blood pressure and heart rate in hypertensive patients after an acute dose and between two doses during long term treatment," Clinical Pharmacology and Therapeutics, vol. 17, no. 4, pp. 400-408, 1975.

[25] P. D. Henry, "Comparative pharmacology of calcium antagonists: nifedipine, verapamil and diltiazem," The American Journal of Cardiology, vol. 46, no. 6, pp. 1047-1058, 1980.

[26] T. L. Owen, I. C. Ehrhart, W. J. Weidner, J. B. Scott, and F. J. Haddy, "Effects of indomethacin on local blood flow regulation in canine heart and kidney," Proceedings of the Society for Experimental Biology and Medicine, vol. 149, no. 4, pp. 871-876, 1975.

[27] S. E. Burke, A. M. Lefer, K. C. Nicolaou, G. M. Smith, and J. B. Smith, "Responsiveness of platelets and coronary arteries from different species to synthetic thromboxane and prostaglandin endoperoxide analogues," The British Journal of Pharmacology, vol. 78, no. 2, pp. 287-292, 1983.

[28] K. Bayne, "Revised guide for the care and use of laboratory animals available. American physiological society," The Physiologist, vol. 39, no. 4, pp. 199-211, 1996.

[29] E. A. Booth, N. R. Obeid, and B. R. Lucchesi, "Activation of estrogen receptor- $\alpha$ protects the in vivo rabbit heart from ischemia-reperfusion injury," The American Journal of Physiology-Heart and Circulatory Physiology, vol. 289, no. 5, pp. H2039-H2047, 2005.

[30] C. Hocht, L. Opezzo, S. Gorzalczany, G. Bramuglia, and C. Tiara, "Una aproximación cinética y dinámica de metildopa en ratas con coartación aórtica mediante microdiálisis," Revista Argentina de Cardiologia, vol. 67, pp. 769-773, 1999.

[31] M. E. Herr and F. W. Heyl, “Enamine' derivatives of steroidal carbonyl compounds. III. The synthesis of C11-oxygenated testosterones," Journal of the American Chemical Society, vol. 75, no. 23, pp. 5927-5930, 1953.

[32] D. E. Stevenson, J. N. Wright, and M. Akhtar, "Synthesis of 19-functionalised derivatives of $16 \alpha$-hydroxy-testosterone: mechanistic studies on oestriol biosynthesis," Journal of the Chemical Society-Chemical Communications, vol. 16, pp. 10781080, 1985.

[33] A. K. Shirayev, I. K. Moiseev, and S. S. Karpeev, "Synthesis and cis/trans isomerism of N-alkyl-1,3-oxathiolane-2-imines," Arkivoc, vol. 2005, no. 4, pp. 199-207, 2005. 
[34] D. J. Uppiah, M. G. Bhowon, and S. J. Laulloo, "Solventless synthesis of imines derived from diphenyldisulphide diamine or p-Vanillin," E-Journal of Chemistry, vol. 6, no. 1, pp. S195S200, 2009.

[35] D. Bouïs, G. A. P. Hospers, C. Meijer, G. Molema, and N. H. Mulder, "Endothelium in vitro: a review of human vascular endothelial cell lines for blood vessel-related research," Angiogenesis, vol. 4, no. 2, pp. 91-102, 2001.

[36] S. Beer, M. Reincke, M. Kral et al., "Susceptibility to cardiac ischemia/reperfusion injury is modulated by chronic estrogen status," Journal of Cardiovascular Pharmacology, vol. 40, no. 3, pp. 420-428, 2002.

[37] L. Figueroa-Valverde, F. Díaz-Cedillo, M. López-Ramos, E. García-Cervera, and K. Quijano-Ascencio, "Inotropic activity induced by carbamazepine-alkyne derivative in an isolated heart model and perfused to constant flow," Biomedica, vol. 31, no. 2, pp. 232-241, 2011.

[38] L. Figueroa-Valverde, H. Luna, C. Castillo-Henkel, O. MuñozGarcia, T. Morato-Cartagena, and G. Ceballos-Reyes, "Synthesis and evaluation of the cardiovascular effects of two, membrane impermeant, macromolecular complexes of dextrantestosterone," Steroids, vol. 67, no. 7, pp. 611-619, 2002.

[39] S. J. Hutchison, A. E. M. Browne, E. Ko et al., "Dehydroepiandrosterone sulfate induces acute vasodilation of porcine coronary arteries in vitro and in vivo," Journal of Cardiovascular Pharmacology, vol. 46, no. 3, pp. 325-332, 2005.

[40] J. Tan, Y. Sharief, K. G. Hamil et al., "Dehydroepiandrosterone activates mutant androgen receptors expressed in the androgen-dependent human prostate cancer xenograft CWR22 and LNCaP cells," Molecular Endocrinology, vol. 11, no. 4, pp. 450-459, 1997.

[41] J. J. Lilley, J. Golden, and R. A. Stone, "Adrenergic regulation of blood pressure in chronic renal failure," Journal of Clinical Investigation, vol. 57, no. 5, pp. 1190-1200, 1976.

[42] L. Figueroa-Valverde, F. Díaz-Cedillo, E. García-Cervera et al., "Positive inotropic activity induced by a dehydroisoandrosterone derivative in isolated rat heart model," Archives of Pharmacal Research, vol. 36, no. 10, pp. 1270-1278, 2013.

[43] C. Seillan, C. Ody, F. Russo-Marie, and D. Duval, "Differential of sex steroids of prostaglandin secretion by male and female cultured piglet endothelial cells," Prostaglandins, vol. 26, no. 1, pp. 3-12, 1983.

[44] Y. Yokoyama, H. Xu, N. Kresge et al., "Role of thromboxane A2 in early BDL-induced portal hypertension," The American Journal of Physiology-Gastrointestinal and Liver Physiology, vol. 284, no. 3, pp. G453-G460, 2003.

[45] P. D. Hirsh, L. D. Hillis, W. B. Campbell, B. G. Firth, and J. T. Willerson, "Release of prostaglandins and thromboxane into the coronary circulation in patients with ischemic heart disease," The New England Journal of Medicine, vol. 304, no. 12, pp. 685-691, 1981. 

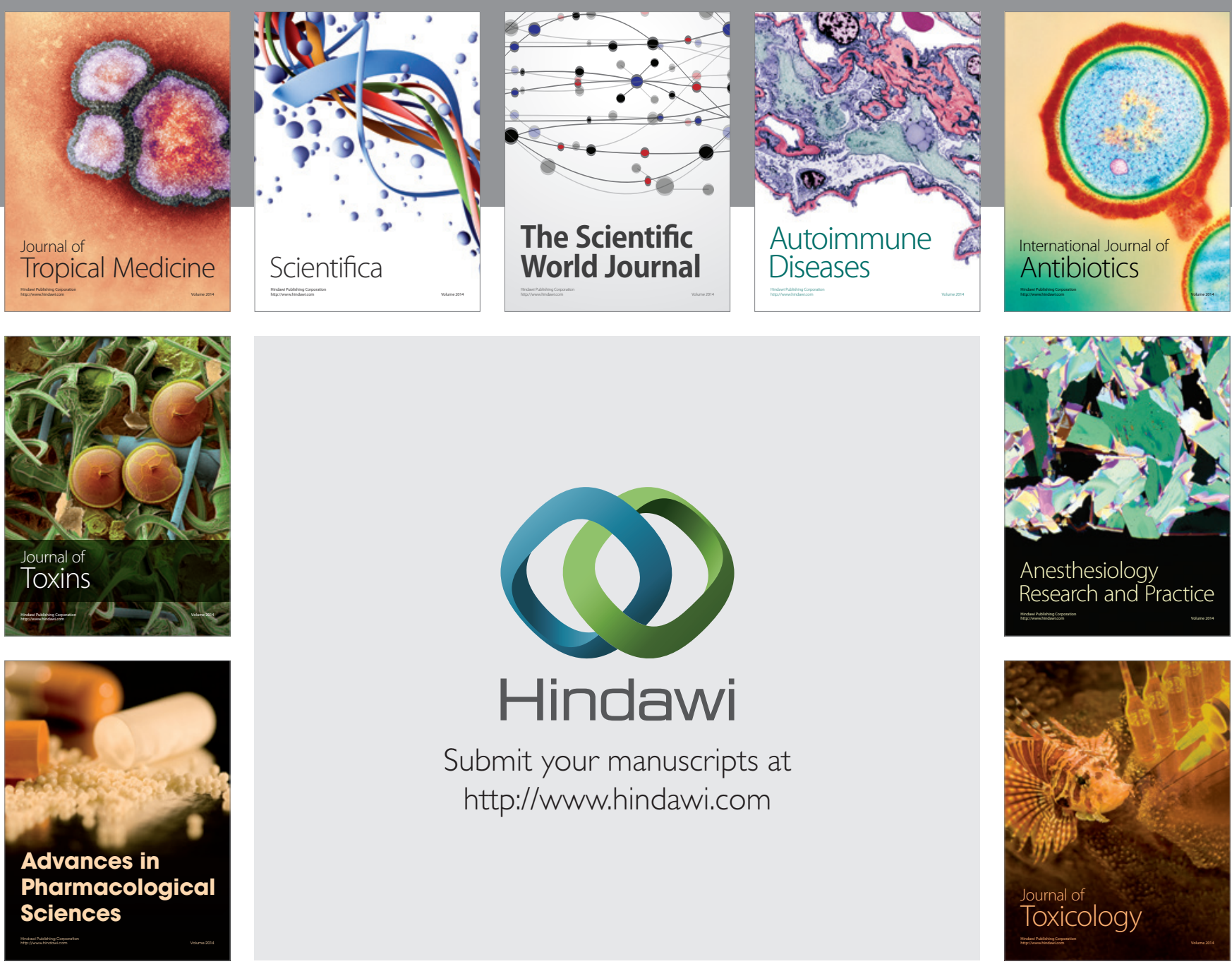

\section{Hindawi}

Submit your manuscripts at

http://www.hindawi.com
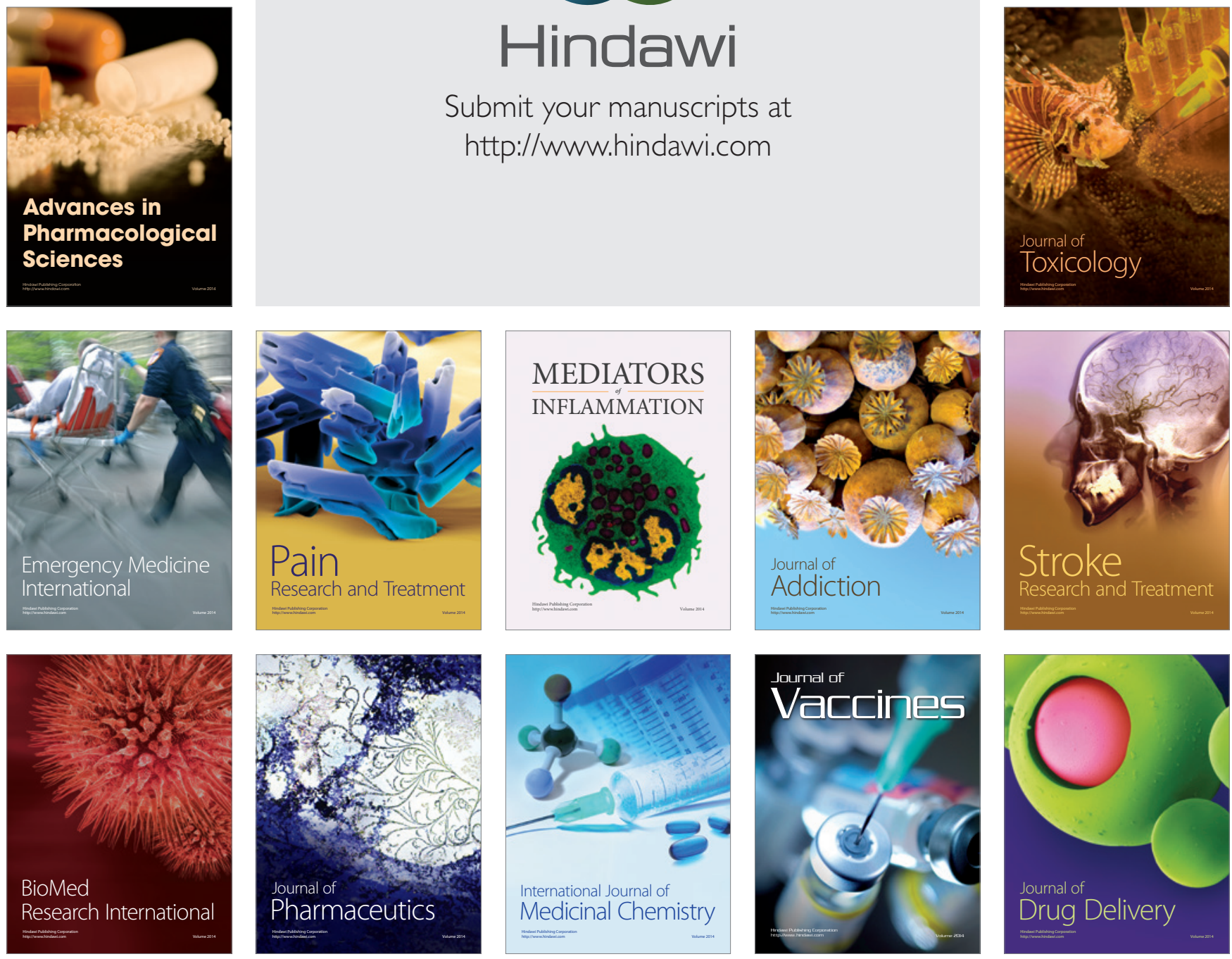